\title{
Human brain arteriovenous malformation: an analysis of differential expressed genes
}

Xing Liu', Guolu Meng ${ }^{2,3^{*}}$, Tengfei Yu ${ }^{2,3}$, Xiangjiang Lin ${ }^{2,3}$, Liwei Zhang ${ }^{2,3}$, Xiaobin Fei ${ }^{2,4}$, Junting Zhang ${ }^{2,3}$, Zhen $\mathrm{Wu}^{2,3}$, Shengze Deng ${ }^{2,3}$, Shunlin Ren ${ }^{2,3,5}$, Shuo Wang ${ }^{2,3}$ and Jizong Zhao ${ }^{2,3}$

\begin{abstract}
Background: Much still remains unknown about the pathogenesis of brain arteriovenous malformations (AVMs). Previous studies have revealed the abnormal expression of various angiogenesis-related genes in AVMs. To further understand this disease, we sought to identify genes differently expressed in AVMs by means of the gene microarray technique.

Methods: Nine AVMs specimen and nine samples of normal vessels are collected. Total RNA isolated from these specimen is hybridized with Oligonucleotide array and gene analysis was conducted. Analyzing data with the help of significance analysis of microarrays (SAM) and a free web-based molecular annotation system 3.0 (MAS 3.0).

Results: The SAM method identify 37 gene significantly up-regulated and 10 genes down-regulated in AVMs. Conclusions: Among those genes, VACN, SPARK and ARHGAP18 seem to play a facilitating role during the genesis of AVMs. Multiple pathways, as MAPK pathway, may also be involved.
\end{abstract}

Keywords: Brain arteriovenous malformations, Gene microarray technique, VCAN, SPARK, ARHGAP18, MAPK pathway

\section{Background}

Arteriovenous malformations (AVMs) is a vascular malformation mainly happens in the central nervous system. Though AVMs only occurs at $0.01 \%$ of the population, it accounting for $3 \%$ of strokes and $9 \%$ of subarachnoid hemorrhages [1], leading to catastrophic health problems. Pathologically, AVMs are complexes of some curved vessels directly connect between the arteries and veins, lacking the intervening capillaries [2]. For this feature, the high-pressure blood flow from the arteries drains directly into venous system, leading to venous engorgement which resulting in edema and irritating the surrounding brain tissue, consequently causing clinical symptoms [3, 4]. Previously, AVMs is treated as a kind of congenital disease. Recent research reveals it could be a developing one [5]. AVMs' genesis is not fully revealed

\footnotetext{
* Correspondence: mengguolu@sina.com; guolumeng111@163.com ${ }^{2}$ Department of Neurosurgery, Beijing Tiantan Hospital, Capital Medical University, 6 Tiantan Xili, Chongwen District, Beijing 100050, People's Republic of China

${ }^{3}$ China National Clinical Research for Neurological Diseases, Beijing, People's

Republic of China

Full list of author information is available at the end of the article
}

yet. In this trial, we collect 9 AVMs samples and 9 normal vessels as control, and use the method of gene microarrays technique to analysis the differential expressed genes in AVMs.

\section{Patients and Methods}

\section{Patients and specimens}

We reviewed all patients treated for AVMs within 10 years from Beijng Tiantan hospital. For excluding the potential impact, patients received interventional treatment or radiotherapy before the resection of the AVMs lesions were excluded. All the AVMs samples were characteristics both pathologically and radiologically. The normal brain vessels were obtained from nine patients receiving temporal lobectomy for medically intractable seizure. Right after resected from the patients, the brain tissues of the AVMs lesions were removed and vessels of the seizure lesions were isolated. All tissues in both groups have been certification of disease by pathologists. 


\section{Method}

\section{Total RNA isolation}

All samples were snap-frozen in liquid nitrogen within 15 min right after they were isolated. In our trial, the RNA was isolated from these specimens with the use of a Trizol method (Invitrogen cooperation, America). After isolation, the total RNA was purified by the NucleoSpin ${ }^{\oplus}$ RNA clean-up kit (Macherey-Nagel cooperation, Germany).

\section{Synthesis of biotin-labeled complementary RNA and hybridization}

Taking $5 \mathrm{mg}$ total RNA as template for transcription to synthesis double chain DNA, double-stranded cDNA is purified by NucleoSpin R Extract 2 kit (Macherey-Nagel cooperation, Germany). And then, we use cDNA to synthesis cRNA, then the AVMs samples were labeled with Cy3-dCTP and Cy5-dCTP (GE healther). All the samples are marked by Universal Human Reference RNA.

\section{CRNA hybridization and washing}

The sample of 2oul is hybridized to the gene microarrays (Illumina, San Diego, CA). The arrays are washed and then they are scanned with dual laser scanner (LuxScan ${ }^{\mathrm{TM}}$ 10K) according the manufacturing protocol and producing an image data.

\section{Real-Time PCR}

Two genes, VACN and SPARC were selected randomly to be confirmed with real-time quantitative reverse transcription PCR (Real-time qRT-PCR) analysis. Total RNA was extracted from 9 AVMs tissues as mentioned previously in microarray experiment. Reactions were carried out by Real-time quantization PCR apparatus (MJ Research, US). Fluorescence changes were monitored after each cycle, and melting curve analysis was done at the end of cycles to verify the identity of PCR product. Average cycle threshold $(\mathrm{Ct})$ values were calculated from triplicate reactions.

\section{Data analysis}

Those image data is transformed into numerical infomation with the help of Luxscan 3.0 image analyzing software (CapitalBio corporation). Then normalize those data by Lowes's method. use two class unpaired in SAM (significant analysis of microarray) to confirm the differential expressed genes (fold change $\geq 1.5$ or $\leq 0.67$, false discovery rate $\leq 0.5$ ). After that, those genes were analyzed by MAS 3.0.To evaluate the reliability of data obtained from the chips, Real Time qRT-PCR was used to check gene VACN and SPARC.

\section{Result}

Forty-six genes met the rank-sum criteria for significance. Table 1 demonstrates the 37 gene up-regulated and 10 gene down-regulated. Analyzed by MAS 3.0, we identify genes and molecular pathways that may have significant impact on the genesis of AVMs as Tables 2 and 3 listed. Those genes involve in multiple pathways, e.g. cell adhesion molecules, tight junction, regulation of actin cytoskeleton and MAPK signaling pathway. Among all those genes and pathways, gene VACN, SPARK and ARHGAP18 and the MAPK pathway are more likely to be related to AVMs.

The Real Time qRT-PCR was used to check the genes (VACN and SPARC) that were selected from the genes we are interested in. the two genes were up-regulated on basis of data obtained from chips. Consequently, the results of the Real Time RT-PCR were completely in agreement with the data obtained from the chips, which demonstrated that the differential expressed genes obtained by the probes were confirmed with high reliability and veracity (Fig. 1).

\section{Discussion}

AVMs is a kind of lesions with an abnormal vessel phenotype. Little is known about its genesis. There has been a growing number of clinical and experimental evidence indicating that it may undergo process of significant vascular remodeling and angiogenesis [6, 7]. Angiogenesis is a biological process describing new capillaries forming from pre-existing vessels [8], consistsing of a sequence of multiple phases including suspension of vessel basement membrane, migration and proliferation of endothelial cells, formation new vessel basement membrane [9]. Numerous regulatory factors must be involved to regulate these process, and they are more likely to be related to growth factors, adhesion molecules, and matrix-degrading enzymes receptor [10]. Previous studies indicate the extracellular matrix, endothelial attachment, migration and proliferation of endothelial cells seem to involve in the developing of AVMs [7].

VCAN gene, containing 15 exons, encodes protein Versican, a protein belongs to the family of hyaluronanbinding proteoglycans, which is regulated by the splicing of the mRNA alternatively $[11,12]$. Versican participates in multiple physical and pathological processes, including cell adhesion and extracellular matrix assembly [13].

Structurally, two globular domains, G1 at the $\mathrm{N}$-terminals and G3 at the C-terminals, consist the core protein of Versican. They can interact with various extracellular matrix [14]. Alternative expression of exons 7 and 8 of the VCAN gene, generates four isoforms of Versican with different number of chondroitin sulfate chains [15]. There is considerable evidence to indicate 
Table 1 Differential expressed genes

\begin{tabular}{|c|c|c|}
\hline Gene & Fold change & q-value (\%) \\
\hline MBP & 4.25 & 0.00 \\
\hline NP_631958 & 3.85 & 0.00 \\
\hline \multirow[t]{2}{*}{ PLP1 } & 3.84 & 4.10 \\
\hline & 3.83 & 0.00 \\
\hline CPM & 3.66 & 0.00 \\
\hline GANC & 3.37 & 2.61 \\
\hline LAM5_HUMAN & 3.09 & 0.00 \\
\hline FKBP5 & 3.06 & 0.00 \\
\hline $\mathrm{EVI} 2 \mathrm{~B}$ & 2.89 & 0.00 \\
\hline RNASE6 & 2.81 & 0.00 \\
\hline SPARC & 2.71 & 0.00 \\
\hline VACN & 2.60 & 2.61 \\
\hline CD3D & 2.57 & 4.10 \\
\hline \multirow[t]{2}{*}{ HCLS1 } & 2.53 & 0.00 \\
\hline & 2.29 & 0.00 \\
\hline \multirow[t]{2}{*}{ SLC31A2 } & 2.22 & 0.00 \\
\hline & 2.12 & 4.10 \\
\hline QPCT & 2.05 & 4.10 \\
\hline ARHGAP18 & 1.97 & 4.10 \\
\hline \multirow[t]{2}{*}{ ZA20D2 } & 1.95 & 0.00 \\
\hline & 1.93 & 2.61 \\
\hline TCA_HUMAN & 1.93 & 0.00 \\
\hline NP_443112 & 1.90 & 2.61 \\
\hline RAB31 & 1.86 & 4.10 \\
\hline NP_060910 & 1.85 & 0.00 \\
\hline FCGR2A & 1.82 & 0.00 \\
\hline IL16 & 1.81 & 0.00 \\
\hline ARHGDIB & 1.80 & 2.61 \\
\hline PRG1 & 1.79 & 0.00 \\
\hline CD53 & 1.79 & 2.61 \\
\hline SAP30 & 1.79 & 0.00 \\
\hline LYN & 1.70 & 2.61 \\
\hline NP_054778 & 1.69 & 4.10 \\
\hline MNDA & 1.67 & 2.61 \\
\hline Clorf38 & 1.62 & 3.53 \\
\hline PREX_HUMAN & 1.62 & 2.61 \\
\hline TMSB4Y & 1.52 & 4.10 \\
\hline \multirow[t]{2}{*}{ PRPSAP1 } & 0.61 & 0.00 \\
\hline & 0.44 & 0.00 \\
\hline \multirow[t]{2}{*}{ FBXO25 } & 0.40 & 0.00 \\
\hline & 0.39 & 3.53 \\
\hline SLC13A3 & 0.38 & 0.00 \\
\hline DUSP2 & 0.37 & 0.00 \\
\hline CRABP2 & 0.23 & 3.53 \\
\hline
\end{tabular}

Table 1 Differential expressed genes (Continued)

\begin{tabular}{lll}
\hline SLC13A4 & 0.21 & 0.00 \\
COCH & 0.19 & 0.00 \\
SERPIND1 & 0.09 & 0.00 \\
\hline
\end{tabular}

the different expressed chondroitin sulfate may be essential in modulating cell adhesion [16].

The activity of Versican could be altered by selective proteolysis of its domain while vascular system is undergoing changes $[17,18]$. Lots of previous studies show that Versican is a kind of anti-adhesive protein, mainly conducted by the G1 domain of this protein. However, some investigations find that the G3 domain of Versican can promote cell adhesion through activating focal adhesion kinase [19]. So it puts forward a possibility that different breakdown products of this protein might influence cell adhesion in different ways [20]. During inflammatory response, Versican can influence the adhesion of myeloid and lymphoid [21]. While entering tissues, they come into contact with some specific components of Versican to promote their adhesion to matrix [22]. Immunohistochemistry demonstrated a striking loss of Versican in the course of vessel developing in the lower dermis [23], which on the contrary may suggest the over expression of Versican can inhibit the normal formation of vessels.

The SPARC gene is a single copy gene with a high degree of evolutionary conservation which has been localized to chromosome 5q31-33. It encode a secreted protein acidic and rich in cysteine (SPARC). SPARC belongs to a group of matrix associated factors that mediate cell matrix interactions [24]. This group of proteins show similar functions for they are found expressed while tissues are undergoing changes in cell matrix or cell-cell contact [25]. SPARC is a highly conserved protein with anti-adhesive properties, inducing cell rounding, inhibiting cell spreading, reorganizing of actin stress fibers, and delaying cell proliferation.

SPARC is found to suppress tumor growing in divers systems [26]. Over expression of SPARC can lead to a better prognosis in neuroplasm, probably due to its antiangiogenic activity reducing the angiogenesis of the lesions [27]. Also, SPARC could promote endothelial cell apoptosis to decrease angiogenesis. A possible way of SPARC inhibiting angiogenesis is to interfere with the binding of pro-angiogenic factors, such as vascular endothelial growth factor [28]. According to various observations in animal models, SPARC could also block the function of some activators of angiogenesis, such as angiogenic growth factors [29].

Previous study has demonstrated evidences for the important role of SPARC in regulating cell proliferation [30]. SPARC can act as inhibitors of cell proliferation in 
Table 2 GO terms of differential expressed genes

\begin{tabular}{|c|c|c|c|c|}
\hline $\mathrm{GO}$ & P-value (\%) & Q-value (\%) & Protein & $\mathrm{FC}$ \\
\hline \multirow[t]{5}{*}{ Protein binding } & $6.34 \mathrm{E}-16$ & 0.0 & HCLS1 & 2.53 \\
\hline & & & LYN & 1.70 \\
\hline & & & ARHGDIB & 1.80 \\
\hline & & & ARHGAP18 & 1.97 \\
\hline & & & CD3D & 2.57 \\
\hline \multirow[t]{2}{*}{ Copper ion binding } & $3.74 \mathrm{E}-05$ & 0.0 & SLC31A2 & 2.21 \\
\hline & & & SPARC & 2.71 \\
\hline \multirow[t]{4}{*}{ Receptor activity } & $7.35 \mathrm{E}-05$ & 0.0 & MS4A6A & 3.83 \\
\hline & & & FCGR2A; & 1.82 \\
\hline & & & ADRA2C & 0.44 \\
\hline & & & KLRK1 & 0.39 \\
\hline \multirow[t]{2}{*}{ Sodium ion binding } & $1.11 \mathrm{E}-04$ & 0.0 & SLC13A3 & 0.38 \\
\hline & & & SLC13A4 & 0.21 \\
\hline \multirow[t]{3}{*}{ Calcium ion binding } & $2.40 \mathrm{E}-04$ & 0.0 & SPARC & 2.71 \\
\hline & & & CAPN3 & 3.37 \\
\hline & & & VCAN & 2.60 \\
\hline \multirow[t]{2}{*}{ Sugar binding } & $2.59 \mathrm{E}-04$ & 0.0 & VCAN & 2.60 \\
\hline & & & KLRK1 & 0.39 \\
\hline Mitogen-activated protein kinase & $3.90 \mathrm{E}-04$ & 0.0 & DUSP2 & 0.36 \\
\hline \multirow[t]{2}{*}{ GTPase activator activity } & 4.23E-04 & 0.0 & ARHGDIB & 1.80 \\
\hline & & & ARHGAP18 & 1.97 \\
\hline \multirow[t]{2}{*}{ Actin binding } & 7.86E-04 & 0.0 & GMFG & 2.29 \\
\hline & & & TMSB4Y & 1.51 \\
\hline \multirow[t]{2}{*}{ Hydrolase activity } & 3.34E-01 & 0.0 & RNASE6 & 2.81 \\
\hline & & & DUSP2 & 0.36 \\
\hline
\end{tabular}

FC Fold Change, $q$-value false positive rate

several types of cells [31]. It has also been observed to inhibit endothelial cell's proliferation, spreading and migration in cells from different sources [32].

ARHGAP18 is another gene we are interested in. This gene encode a novel RhoA GTPase-activating protein (GAP) which involves in cell shape rugelating, cell migrating and spreading. Immunofluorescence analysis revealed that GAP exist in the leading edge of cytoplasm during cell spreading and migration. While the ARHGAP18 gene is absence, the process of cell shape regulating and focal adhesions organization are interrupted. This protein regulate those process through GAP activity

Table 3 Pathway analysis for AVMs' differential expressed genes

\begin{tabular}{|c|c|c|c|c|}
\hline Pathway & P-value (\%) & Q-value (\%) & Gene & FC \\
\hline MAPK signaling pathway & 0.219 & 0.0 & DUSP2 & 0.36 \\
\hline Cell adhesion molecules & 0.113 & 0.0 & VCAN & 2.60 \\
\hline Tight junction & 0.114 & 0.0 & HCLS1 & 2.53 \\
\hline Galactose metabolism & 0.023 & 0.0 & GANC & 3.36 \\
\hline Primary immunodeficiency & 0.031 & 0.0 & CD3D & 2.57 \\
\hline Starch and sucrose metabolism & 0.046 & 0.0 & GANC & 3.36 \\
\hline Pathogenic Escherichia coli infection & 0.048 & 0.0 & HCLS1 & 2.53 \\
\hline Natural killer cell mediated cytotoxicity & 0.116 & 0.0 & KLRK1 & 0.39 \\
\hline Regulation of actin cytoskeleton & 0.178 & 0.0 & TMSB4Y & 1.51 \\
\hline
\end{tabular}

FC Fold Change, $q$-value false positive rate 


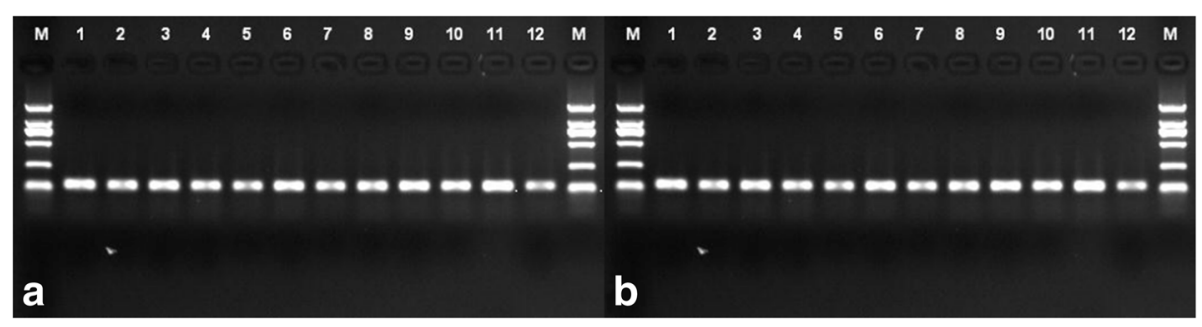

Fig. 1 The results of Real Time RT-PCR ( $\mathbf{a}$ is VACN and $\mathbf{b}$ is SPRRC)

$[33,34]$. Cell shaping and focal adhesion organization are essential procedures to form normal vessel structures.

The Mitogen-activated protein kinase (MAPK) pathway may have an outstanding impact on the process of AVMs' genesis. MAPK pathways could regulate many cellular functions including cell proliferation, differentiation, migration and apoptosis [35]. MAPK signaling pathway provide a connection between transmembrane signaling and gene transcription in response to various environmental factors such as cytokines, growth factors and inflammation. The MAPK pathway can be attenuated by a family of dual specificity MAPK phosphatases. We find a gene named DUSP2 is down-regulated in AVMs samples. This gene expresses a protein belonging to the dual specificity protein phosphatase subfamily that can inactivate their target kinases by dephosphorylating both the phosphoserine/threonine and phosphotyrosine residues. And in turn negatively regulate the MAPK pathway [36].

\section{Conclusion}

The genesis of AVMs is not fully understand yet, our trial has discovered some genes and cell signal pathways that are expressed differently in AVMs that mainly related to process of angiogenesis. We hope those genes' discovery may attract more attention on the research of AVMs.

\section{Abbreviations}

AVMs: Arteriovenous malformations; GAP: GTPase-activating protein; MAPK: The Mitogen-activated protein kinase

\section{Funding}

The study received financial support from the Beijing Nova program of science and technology. The funding organizations had no role in development of the study or the drafting of the manuscript for publication.

\section{Availability of data and materials}

All the data we needed was presented in the tables and figures in the main paper.

\section{Authors' contributions}

$\mathrm{XL}$ carried out the microarray studies and draft the manuscript; GM design the study and draft the manuscript; $X J L$ and $T Y$ carry out the gene microarray analysis; LZ, JZ and ZW participated in the surgery and tissue collecting; XF, SD and SR carried out the PCR studies and drafted the manuscript; ZW and JZZ participated in the study design and coordination. All authors read and approved the final manuscript.

Competing interest

The authors declare that they have no competing interest.

Consent for publication

Not applicable.

Ethics approval and consent to participate

Ethical approval was given by the medical ethics committee of IRB of Beijing Tiantan Hospital Affiliated to Capital Medical University with the following reference number: KY2011-002-02.

And the authors have obtained written informed consent of all the tissues donors.

\section{Author details}

${ }^{1}$ Department of Pediatric Surgery, Yongchuan Hospital of Chongqing Medical University, 439 Xuanhua Road, Yongchuan District, Chongqing, People's Republic of China. ${ }^{2}$ Department of Neurosurgery, Beijing Tiantan Hospital, Capital Medical University, 6 Tiantan Xili, Chongwen District, Beijing 100050, People's Republic of China. ${ }^{3}$ China National Clinical Research for Neurological Diseases, Beijing, People's Republic of China. ${ }^{4}$ Department of Neurosurgery, Jiangyi Hosptial, Medical School of Southeast University, 163 Shoushan street, Jiangyin District, Jiangsu Province, People's Republic of China. ${ }^{5}$ Department of General Surgery, Beijing Tongren Hospital, Capital Medical University, 1 Dongjiaomingxiang, Dongcheng District, Beijing, People's Republic of China.

Received: 27 May 2016 Accepted: 17 November 2016 Published online: 06 December 2016

\section{References}

1. Mortazavi MM, et al. Long-term control of large pontine arteriovenous malformation using gamma knife therapy: a review with illustrative case. Brain Behav. 2013:3(4):329-34.

2. Doppman JL. The nidus concept of spinal cord arteriovenous malformations. A surgical recommendation based upon angiographic observations. Br J Radiol. 1971:44(526):758-63.

3. Valavanis $A$. The role of angiography in the evaluation of cerebral vascular malformations. Neuroimaging Clin N Am. 1996;6(3):679-704.

4. Kim JH. Pathology of epilepsy. Exp Mol Pathol. 2001;70(3):345-67.

5. Morgan MK, et al. Influence of the combination of patient age and deep venous drainage on brain arteriovenous malformation recurrence after surgery. J Neurosurg. 2012;117(5):934-41.

6. Koizumi T, et al. Expression of vascular endothelial growth factors and their receptors in and around intracranial arteriovenous malformations. Neurosurgery. 2002;50(1):117-24. discussion 124-6.

7. Hashimoto T, et al. Evidence of increased endothelial cell turnover in brain arteriovenous malformations. Neurosurgery. 2001;49(1):124-31. discussion $131-2$.

8. Matthay KK, et al. Treatment of high-risk neuroblastoma with intensive chemotherapy, radiotherapy, autologous bone marrow transplantation, and 13-cis-retinoic acid. Children's Cancer Group. N Engl J Med. 1999: 341(16):1165-73.

9. Nagaraju GP, Sharma D. Anti-cancer role of SPARC, an inhibitor of adipogenesis. Cancer Treat Rev. 2011;37(7):559-66. 
10. Roy CS, et al. Targeting angiogenesis for controlling neuroblastoma. J Oncol. 2012;2012:782020.

11. Ito K, et al. Multiple forms of mouse PG-M, a large chondroitin sulfate proteoglycan generated by alternative splicing. J Biol Chem. 1995;270(2): 958-65.

12. Dours-Zimmermann MT, Zimmermann DR. A novel glycosaminoglycan attachment domain identified in two alternative splice variants of human versican. J Biol Chem. 1994;269(52):32992-8.

13. Theocharis AD. Versican in health and disease. Connect Tissue Res. 2008; 49(3):230-4.

14. Wu YJ, et al. The interaction of versican with its binding partners. Cell Res. 2005;15(7):483-94.

15. Schmalfeldt $\mathrm{M}$, et al. Versican $\mathrm{V} 2$ is a major extracellular matrix component of the mature bovine brain. J Biol Chem. 1998;273(25):15758-64.

16. Schmalfeldt $\mathrm{M}$, et al. Brain derived versican V2 is a potent inhibitor of axonal growth. J Cell Sci. 2000;113(Pt 5):807-16.

17. Sandy JD, et al. Versican V1 proteolysis in human aorta in vivo occurs at the Glu441-Ala442 bond, a site that is cleaved by recombinant ADAMTS-1 and ADAMTS-4. J Biol Chem. 2001;276(16):13372-8.

18. Kenagy RD, Plaas AH, Wight TN. Versican degradation and vascular disease. Trends Cardiovasc Med. 2006;16(6):209-15.

19. Ang $L C$, et al. Versican enhances locomotion of astrocytoma cells and reduces cell adhesion through its G1 domain. J Neuropathol Exp Neurol. 1999;58(6):597-605.

20. Lemire $J M$, et al. Overexpression of the $\mathrm{V} 3$ variant of versican alters arterial smooth muscle cell adhesion, migration, and proliferation in vitro. J Cell Physiol. 2002;190(1):38-45.

21. Gill S, Wight TN, Frevert CW. Proteoglycans: key regulators of pulmonary inflammation and the innate immune response to lung infection. Anat Rec (Hoboken). 2010;293(6):968-81.

22. Wight TN, Kang I, Merrilees MJ. Versican and the control of inflammation. Matrix Biol. 2014;35:152-61.

23. Fu Y, et al. Proteolytic cleavage of versican and involvement of ADAMTS-1 in VEGF-ANPF-induced pathological angiogenesis. J Histochem Cytochem. 2011;59(5):463-73.

24. Lane TF, et al. SPARC is a source of copper-binding peptides that stimulate angiogenesis. J Cell Biol. 1994:125(4):929-43.

25. Bornstein P. Diversity of function is inherent in matricellular proteins: an appraisal of thrombospondin 1. J Cell Biol. 1995:130(3):503-6.

26. Framson PE, Sage EH. SPARC and tumor growth: where the seed meets the soil? J Cell Biochem. 2004;92(4):679-90.

27. Chlenski A, et al. SPARC is a key Schwannian-derived inhibitor controlling neuroblastoma tumor angiogenesis. Cancer Res. 2002;62(24):7357-63.

28. Chlenski A, et al. Anti-angiogenic SPARC peptides inhibit progression of neuroblastoma tumors. Mol Cancer. 2010;9:138.

29. Yunker CK, et al. SPARC-induced increase in glioma matrix and decrease in vascularity are associated with reduced VEGF expression and secretion. Int J Cancer. 2008;122(12):2735-43.

30. Tai IT, Tang MJ. SPARC in cancer biology: its role in cancer progression and potential for therapy. Drug Resist Updat. 2008:11(6):231-46.

31. Podhajcer OL, et al. The role of the matricellular protein SPARC in the dynamic interaction between the tumor and the host. Cancer Metastasis Rev. 2008;27(4):691-705.

32. Said $\mathrm{N}$, et al. Normalization of the ovarian cancer microenvironment by SPARC. Mol Cancer Res. 2007:5(10):1015-30.

33. Maeda M, et al. ARHGAP18, a GTPase-activating protein for RhoA, controls cell shape, spreading, and motility. Mol Biol Cell. 2011;22(20):3840-52.

34. Barrett T, et al. The structure of the GTPase-activating domain from p50rhoGAP. Nature. 1997:385(6615):458-61.

35. Koul HK, Pal M, Koul S. Role of p38 MAP kinase signal transduction in solid tumors. Genes Cancer. 2013:4(9-10):342-59.

36. Faroog A, et al. Solution structure of the MAPK phosphatase PAC-1 catalytic domain. Insights into substrate-induced enzymatic activation of MKP. Structure. 2003:11(2):155-64.

\section{Submit your next manuscript to BioMed Central and we will help you at every step:}

- We accept pre-submission inquiries

- Our selector tool helps you to find the most relevant journal

- We provide round the clock customer support

- Convenient online submission

- Thorough peer review

- Inclusion in PubMed and all major indexing services

- Maximum visibility for your research

Submit your manuscript at www.biomedcentral.com/submit

) Biomed Central 